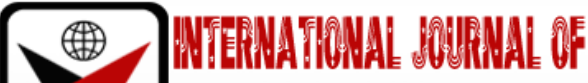

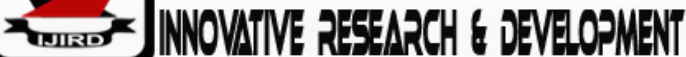

ISSN 2278-0211 (Online)

\section{Computer Usage and Risk Attendance among Students of Office and Information Management and Medical Laboratory Science Students: A Comparative Study}

\begin{tabular}{c} 
Gbaranor Kekii Barinua \\
Lecturer, Department of Human Physiology, \\
Rivers State University, Port Harcourt, Nigeria \\
Barinua-Gbaranor Nazor Priscilla \\
Ph.D. Student, Department of Office and Information Management, \\
Rivers State University, Port Harcourt, Nigeria \\
Agara Humphrey N. \\
Lecturer, Department of Medical Biochemistry, \\
Rivers State University, Port Harcourt Nigeria \\
Alasia Onisojime Moses \\
Lecturer, Department of Pharmacology, \\
Niger Delta University, Bayelsa State, Nigeria \\
Amadi Nyemachi Choice \\
Lecturer, Department of Nursing Science, \\
Rivers State University, Port Harcourt, Nigeria \\
Iboroma Dumoateli \\
Lecturer, Department ofHuman Anatomy \\
Rivers State University, Port Harcourt, Nigeria \\
Nonju Imaobong Ibifubara \\
Lecturer, Department of Human Physiology, \\
Rivers State University, Port Harcourt, Nigeria \\
Hebinuchi Amadi \\
Lecturer, Department ofPharnacology and Therapeutics, \\
Rivers State University, Port Harcourt, Nigeria \\
\hline
\end{tabular}

\begin{abstract}
:
Information and communication technology is an important aspect of education across the global and is necessary that every student and non-students should know. There is an increase in risk associated with computer usage. This study was carried out to $x$-ray the risk arising from computer usage. The aim of this study is to ascertain computer usage and risk attendance among students of Office and Information Management and Laboratory Science Students, a comparative study.The study revealed that $72.57 \%$ (82/113) were between the ages 19-25, 22.12\% (25/113) were between $26-32$ and $5.31 \%$ (6/113) were between 33-36 years. Again, 73.21\% (82/112) of the participants were students alone, while 26.79\% (30/112) were both students and working class. 53.47\% (54/101) of the students were from the department of Office and Information Management while 46.53\% (47/101) were from the department of Medical Laboratory Students. 95.56\% (108/113) of the students are computer literate and $4.42 \%$ (5/113) of the students are non-computer literate. However, 46.49\% (53/114) of the participating students sit erect and 53.51\% (61/114) bend forward while operating the computers and 56.14\% (64/114) of the students experienced pain and 43.86\% (50/114) do not experienced pain. 55.70\% (44/79) of the participants have back pain, 32.91\% (26/79) have waist pain and $11.39 \%$ (9/79) have leg's pain.47.27\% (52/110) of the students maintain sitting distance of 10cm from the computer's screen, 40\% (44/110) maintained a distance of $15 \mathrm{~cm}$ and $12.73 \%(14 / 110)$ maintained a distance of $20 \mathrm{~cm}$. Also, 49.45\% (45/91) of the student's experienced eyes pain, 29.6\% (27/91) experienced eyes discharge, 12.09\% (11/91) experienced eye itching and 8.79\% (8/91) experienced red eyes.
\end{abstract}

Keywords: Computer, risk, attendance comparative

\section{Introduction}

Information communication and technologies (ICT) at present are influencing every aspect of human life and they are playing important roles in work places, business, education, and entertainment(K. Ratheeswari, 2018). Several people recognize ICTs as catalysts for change; change in working conditions, handling and exchanging information, teaching 
methods, learning approaches, scientific research, and in accessing information communication technologies (K. Ratheeswari, 2018).

Computer is widely use across the world in all sectors such as health, education, agriculture and industries. Computer training is paramount because you must undergo some levels of training before you operate it, and while undergoing the training you could develop certain symptoms of disease or expose to risk factors of certain illness.

Computer work is commonly believed to be a new risk factor for the development of musculoskeletal disorders (MSDs), which generally is the most frequently diagnosed occupational diseases in Estonia (Estonian Health Board 2012) and other European countries (European Agency for Safety and Health at Work, 2010). Occupational use of computers has increased rapidly over recent decades, and has been linked with various musculoskeletal disorders (Kristel et al, 2014). Study by Kristel et al, 2014 revealed a high prevalence of musculoskeletal pain, in the neck and low back, among Estonian computer users.

ICTs are making dynamic changes in society. They are influencing all aspects of life. The influences are felt more and more at schools. Because ICTs provide both students and teachers with more opportunities in adapting learning and teaching to individual needs, society is, forcing schools aptly respond to this technical innovation (Kristel et al, 2014).

\section{Materials and Methods}

This is a cross-sectional study involving students from two departments- Office and Information Management students and Medical Laboratory Sciencestudents. The age range was between 19-50 years. Well-structured questionnaires containing demographics, knowledge aboutcomputerand attendance risk were administered to each participant. The participants were educated on how to fill the questionnaires and each student had one questionnaire to fill appropriately and independently after instructions were given to them by the researchers. Statistical analysis of data was done using Microsoft Excel. P value $<0.05$ was considered significant for data.

\section{Results}

The participants ages were between 19 -50 yeas and they are students from both Office and Information Management (OIM) and Medical Laboratory Science (MLS) departments. Our finding shows that 73.21\% (82/112) of the respondents were students only and $26.79 \%$ (30/112) were students and they were also working.53.46\% (54/101) of the respondents were from OIM department while 46.53\% (47/101) were from MLS department. The findings show that 95.6\% (108/113) of the respondents were computer literate and 4.4\% (5/113) were not computer literate. The study revealed that $52.68 \%(59 / 112)$ of the respondents used computer every day, 25.89\% (29/112) used computer once a week and $21.43 \%$ (24/112) used computer twice per week.92.73\% 102/110) of the respondents operates computer between 1-5 hours, 6.36\% (7/110) operates computer between 6-8 hours and 0.91\% (1/110) operates computer > 12 hours. The study shows that $46.49 \%$ (53/114) of the students sit erect while and $53.51 \%$ bend forward while operating computer. 56.14\% (64/50) of the respondents experienced pains from which $53.20 \%$ (34/64) of them were OIM students while 46.8\% (30/64) were students from MLS. 43.86\% (50/114) of the students do not experienced pain while operating computer. $12.73 \%(14 / 110)$ of the students maintain $20 \mathrm{~cm}$ distance from computer.

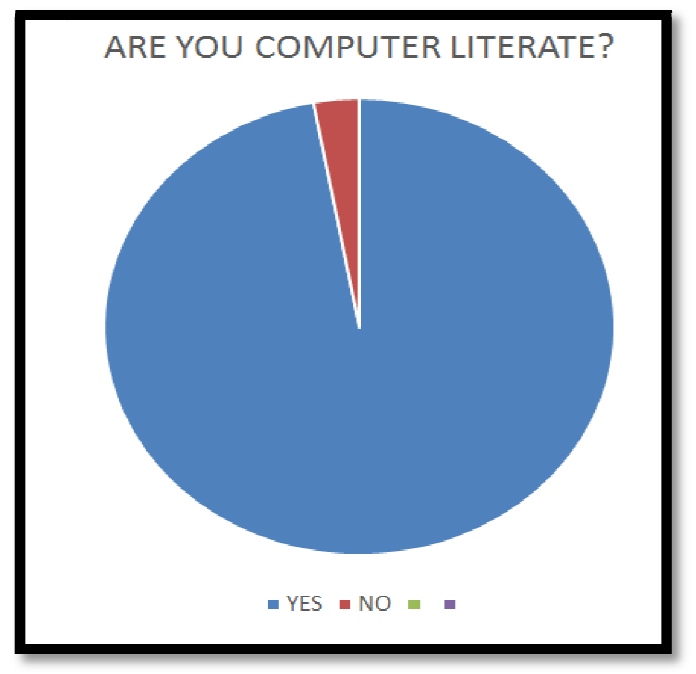

Figure 1 


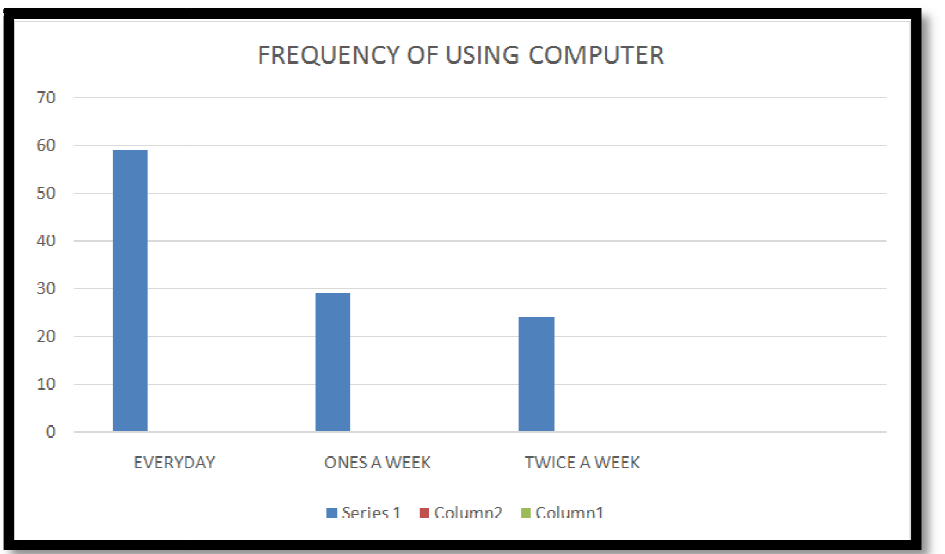

Figure 2

\begin{tabular}{|c|c|c|}
\hline 1-5 HOURS & $\mathbf{6 - 8}$ HOURS & >12 HOURS \\
\hline 102 & 7 & 1 \\
\hline $92.73 \%$ & $6.36 \%$ & $0.91 \%$ \\
\hline
\end{tabular}

Table 1

\begin{tabular}{|c|c|}
\hline ERECT & BEND FORWARD \\
\hline 53 & 61 \\
\hline $46.49 \%$ & $53.51 \%$ \\
\hline \multicolumn{2}{|c|}{ Table 2} \\
\hline
\end{tabular}

\begin{tabular}{|c|c|c|c|}
\hline \multicolumn{2}{|l|}{ YES } & \multicolumn{2}{|l|}{ NO } \\
\hline \multicolumn{2}{|l|}{64} & \multicolumn{2}{|l|}{50} \\
\hline \multicolumn{2}{|c|}{$56.14 \%$} & \multicolumn{2}{|c|}{$43.86 \%$} \\
\hline MLS & OIM & OIM & MLS \\
\hline 30 & 34 & 28 & 22 \\
\hline $46.8 \%$ & $53.2 \%$ & $56 \%$ & $44 \%$ \\
\hline
\end{tabular}

Table 3

\begin{tabular}{|c|c|c|c|c|c|c|c|}
\hline \multicolumn{2}{|c|}{ Eyes Pain } & \multicolumn{2}{c|}{ Eyes Discharge } & \multicolumn{2}{c|}{ Eye Itching } & \multicolumn{2}{c|}{ Red Eye } \\
\hline \multicolumn{2}{|c|}{45} & \multicolumn{2}{c|}{27} & \multicolumn{2}{c|}{11} & \multicolumn{2}{c|}{8} \\
\hline \multicolumn{2}{|c|}{$49.45 \%$} & \multicolumn{2}{c|}{$29.67 \%$} & \multicolumn{2}{c|}{$12.09 \%$} & \multicolumn{2}{c|}{$8.79 \%$} \\
\hline OIM & MLS & OIM & MLS & OIM & MLS & OIM & MLS \\
\hline 32 & 13 & 18 & 9 & 7 & 4 & 7 & 1 \\
\hline $71 \%$ & $29 \%$ & $66.6 \%$ & $33.4 \%$ & $63.6 \%$ & $36.4 \%$ & $87.5 \%$ & $12.5 \%$ \\
\hline
\end{tabular}

Table 4

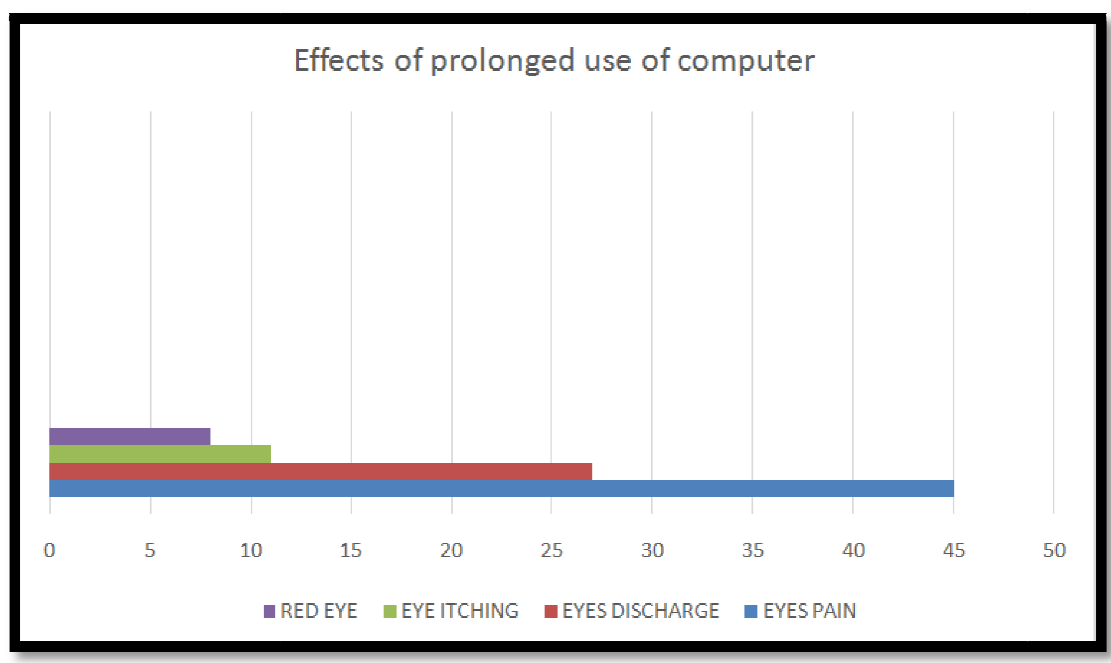

Figure 3 


\section{Discussion}

The use of computer in daily activities across the globe has increased in recent time. The result shows that over $95 \%$ of the entire population (respondents)are computer literates and they spend an average of one to five hours daily on the computer. Students from Office and Information management (OIM) appears to have better use of computers than those in Medical Laboratory Science (MLS). About 27\% of the population used computes with poor lighting room. Only very few students $(12.73 \%)$ from the population maintain up to $20 \mathrm{~cm}$ distance from the computer screen. Using computer every day and for a long period without proper condition is a fertile ground for development of certain risk factors affecting the body system of the computer's users. The study revealed that $52.68 \%$ of the students(respondents) uses computer every day and $92.73 \%$ of them(students) operates computer between 1 to 5 hours every day (Table 2). Comparing the attendance risks, students from Office and Information Management are more predisposed to the negative effects (back pain, waist pain, eyes discomfort, eyes discharge, eye itching and red eye) of prolonged use of computers while students of Medical Laboratory Science are more aware of the dangers associated with prolonged use of Computers (Tables 4 and 5). About 95\% of the students from Office and Information Management are exposed to two or more risks associated with the use of computers while those of their counterpart from Medical Laboratory Science department is about 86\%. The research shows that those who are students and also working face more risks as they are exposed to computers both at work and in school. 25\% of the population experience swollen legs while sitting to operate the computer with Office and Information Management having a greater percentage of 19\%. However, it is believed that students from Office and Information Management (OIM) are prone to computers usage than students from Medical Laboratory Science(MLS) department and this could be the reason while OIM students are exposed to attendance risks than their counterpart from MLS. These attendance risks from prolonged exposure to computers can affect productivity. This is because when you have red eye and eye discharge due to prolong exposure, you cannot face the computer and this now affect your activities leading to low productivity.

\section{Conclusion}

This study revealed that students from Office and Information Management (OIM) are more prone to attendance risks due to prolong exposure to computer usage than their counterpart students from Medical Laboratory Science (MLS) department.

\section{References}

i. KristelOha, *LiinaAnimägi, MatiPääsuke, David Coggon and EdaMerisalu (2014). Individual and work-related risk factors for musculoskeletal pain: a cross-sectional study among Estonian computer users

ii. Estonian Health Board (2012): Review of occupational diseases and work-related disease. [http://www.terviseamet.ee/fileadmin/dok/Tervishoid/ tootervis/toost_pohjustatud_haigused_2012.pdf]

iii. European Agency for Safety and Health at Work: OSH in figures: work-related musculoskeletal disorders in the EU - facts and figures. European risk observatory report 2010. [https://osha.europa.eu/en/ publications/reports/TER009009ENC/view]

iv. K. Ratheeswari, (2018). Information Communication Technology in Education. Journal of Applied and Advanced Research, 2018: 3(Suppl. 1) S45-S47 https://dx.doi.org/10.21839/jaar.2018.v3S1.169 ISSN 25199412 / (C) 2018 Phoenix Research Publishers. 